\title{
DESIGN AND STATISTICAL OPTIMIZATION OF A BILAYERED TABLET OF METOPROLOL SUCCINATE SUSTAINED RELEASE AND ATORVASTATIN CALCIUM IMMEDIATE RELEASE: ONCE A DAY FORMULATION IN THE MANAGEMENT OF HYPERTENSION
}

\author{
PEARL PIRES DIGHE ${ }^{1,2 *}$, TANK HM ${ }^{3}$ \\ ${ }^{1}$ Department of PES's Rajaram and Tarabai Bandekar College of Pharmacy, Ponda, Goa, India. ${ }^{2}$ Department of School of Pharmacy, RK \\ University, Rajkot-Bhavnagar Highway, Rajkot, Gujarat, India. ${ }^{3}$ Department of Matushree V. B. Manvar College of Pharmacy, \\ Dumiyani, Upleta, Rajkot, Gujarat, India. Email: pirespearl@gmail.com \\ Received: 07 December 2017, Revised and Accepted: 09 December 2017
}

ABSTRACT

Objective: The current study involves the fabrication of oral bilayer matrix designs of a combination of two drugs, metoprolol succinate and atorvastatin calcium, the optimization of their in vitro release and characterization using the design expert software. Metoprolol succinate, a $\beta_{1}-$ selective adrenergic receptor blocking agent, is used in the management of hypertension has a half-life of approximately $4-5 \mathrm{~h}$; thus, there is the need to use extended-release formulation for prolonged action. Atorvastatin is a hydroxymethylglutaryl-coenzyme A reductase inhibitor, an antilipidemic, used to lower blood cholesterol. The rationale for this fixed-dose combination is to coadminister two drugs acting by different mechanisms of action together, reduce dosing frequency, and increase patient compliance.

Methods: A $3^{2}$ factorial design was selected to analyze the effect of critical factors, polymer concentration of Kollidon sustained release (SR), and Eudragit RS and their interaction on the in vitro release of the SR part containing metoprolol succinate. The drug release at $2 \mathrm{~h} \mathrm{(Q2),} 8 \mathrm{~h}(\mathrm{Q} 8)$, and 20 h (Q20) was taken as responses. The blends of both layers were prepared, evaluated for precompression characteristics, and compressed by direct compression. The compressed bilayer tablets were evaluated for their hardness, weight variation, friability, content uniformity, diameter, and in vitro release.

Result and Conclusion: The release profile indicates Higuchi's kinetics. Contour and surface response plots show significant interaction among the formulation variables. Formulation MS06 containing $70 \mathrm{mg}$ Kollidon SR and $10 \mathrm{mg}$ Eurdragit RS was found to be the optimized formulation, controlling the drug release for a $24 \mathrm{~h}$ period.

Keywords: Bilayer tablet, Metoprolol succinate, Atorvastatin calcium, Kollidon sustained release, Eudragit RS, Design expert.

(c) 2018 The Authors. Published by Innovare Academic Sciences Pvt Ltd. This is an open access article under the CC BY license (http://creativecommons. org/licenses/by/4. 0/) DOI: http://dx.doi.org/10.22159/ajpcr.2018.v11i3.23528

\section{INTRODUCTION}

The multilayered tablet concept has been utilized to develop sustained release (SR) formulations and coadministers two drugs as a fixed-dose combination [1].

Hypertension is the most common cardiovascular disease. The prevalence of hypertension increases with advancing age. Metoprolol succinate is a $\beta_{1}$-selective adrenergic receptor blocking agent used in the management of hypertension. The half-life of drug is relatively short, approximately 4-6 h, and in normal course of therapy, drug administration is required every $4-6 \mathrm{~h}$, thus there is the need for the use of extended-release formulation for prolong action and to improve patient compliance $[2,3]$.

Antilipidemic agents are an important group of drugs for the treatment of ischemia and hypertension. Atorvastatin is a hydroxymethylglutarylcoenzyme A reductase inhibitor and has a longer duration of action, and the initial effects are cumulative over many days and moreover for patient compliance in case of angina patients; a rapid onset of action is necessary for immediate pain relief $[4,5]$.

The present study encompasses a combination drug therapy, recommended for treatment of hypertension to allow medications of different mechanisms of action to complement each other and together effectively lower blood pressure at lower than maximum doses of each.

The rationale for this fixed-dose combination is to coadminister two drugs acting by different mechanisms of action together reduce dosing frequency and increase patient compliance.
Kollidon SR is a relatively new extended-release matrix excipient. It consists of $80 \%$ polyvinyl acetate (PVA) and $20 \%$ povidone (PVP) in a physical mixture, stabilized with $0.8 \%$ sodium lauryl sulfate (SLS), and $0.2 \%$ colloidal silica. It shows excellent flowability and can be used as an excipient for direct compression. The amorphous nature of PVA along with its unusually low glass transition temperature imparts unique characteristics to a matrix formulation. The SR properties are unaffected by ions or salts [6]. The current work aims at design and statistical optimization using $3^{2}$ factorial approach (using Stat Ease Inc., Minneapolis, MN, USA, Design Expert ${ }^{\circledR} 10$ software) of a bilayer tablets of atorvastatin calcium as immediate release (IR) and metoprolol succinate as SR using Kollidon SR as a novel directly compressible SR polymer.

\section{MATERIALS AND METHODS}

Atorvastatin calcium was gifted by Wanbury Ltd., Mumbai, metoprolol succinate was gifted by Dr. Reddy's Ltd., Hyderabad, Kollidon SR was gifted by VerGo Pharma, Goa, Eudragit RS by Evonik India, Mumbai, and MCC pH 102 and other excipients from Arihant Chemicals, Mumbai.

\section{Methodology}

Formulation of atorvastatin calcium IR component

The dose of the drug in the IR layer is $10 \mathrm{mg}$. The blend for IR layer was prepared by mixing drug with super disintegrant crospovidone and surfactant SLS geometrically and subsequently adding other ingredients as per Table 1 . The ingredients were mixed in mortar and pestle for 15 min, mixture passed through sieve\# 80 , and finally, magnesium stearate and aerosil were blended into and mixed thoroughly. The 
blends were evaluated for precompression parameters such as bulk density, tapped density, angle of repose, and Carr's compressibility index. The final weight of the tablet was $110 \mathrm{mg}$, compressed using Rimek Mini Press II MT (Karnavati Engineering Private Ltd.) [7]

Formulation of metoprolol succinate SR component using $3^{2}$ factorial design

To design the SR layer for the bilayer tablet, a $3^{2}$ full factorial design containing two factors at three levels was applied. Different preliminary trial batches were taken to ascertain concentrations of independent variables to be used in $3^{2}$ factorial design. The independent variables used were a concentration of Kollidon SR and concentration of Eudragit RS. Table 2 summarizes the level of variables according to the experimental design. The amount of Kollidon SR per tablet is chosen at three levels from $30 \mathrm{mg}$ to $50 \mathrm{mg}$ to $70 \mathrm{mg}$ per tablet. The effect of Eudragit RS was studied at three levels $(0,10$, and $20 \mathrm{mg})$ to check its effect on drug release.

The polynomial equation generated by the design software Design Expert 10, State Ease Inc., is as follows:

$\mathrm{Y}=\mathrm{b}_{0}+\mathrm{b}_{1} \mathrm{X}_{1}+\mathrm{b}_{2} \mathrm{X}_{2}+\mathrm{b}_{12} \mathrm{X}_{1} \mathrm{X}_{2}+\mathrm{b}_{11} \mathrm{X}_{1}^{2}+\mathrm{b}_{22} \mathrm{X}_{2}^{2}$

Where, $\mathrm{Y}$ is a response (dependent variable), $\mathrm{b}_{0}$ is an intercept, $\mathrm{b}_{1}$ to $\mathrm{b}_{22}$ are regression coefficients, and $\mathrm{X}_{1}$ and $\mathrm{X}_{2}$ are independent formulation variables

Table 1: Formulation of atorvastatin calcium blends

\begin{tabular}{lllll}
\hline \multirow{2}{*}{ Ingredients (mg/tab) } & \multicolumn{2}{l}{ Formulations } & & \\
\cline { 2 - 5 } & AT01 & AT02 & AT03 & AT04 \\
\hline Atorvastatin calcium & 10 & 10 & 10 & 10 \\
Crospovidone & 10 & 10 & 5 & 5 \\
SLS & 1 & 0.5 & 1 & 0.5 \\
MCC pH 102 & 30 & 30 & 30 & 30 \\
Lactose & 50 & 50.5 & 55 & 55.5 \\
Calcium carbonate & 8 & 8 & 8 & 8 \\
Magnesium stearate & 0.5 & 0.5 & 0.5 & 0.5 \\
Aerosil & 0.5 & 0.5 & 0.5 & 0.5 \\
Total tablet weight (mg) & 110 & 110 & 110 & 110 \\
\hline
\end{tabular}

SLS: Sodium lauryl sulfate, MCC: Microcrystalline cellulose

Table 2: Experimental design for Metoprolol succinate component as per design expert

\begin{tabular}{lll}
\hline $\begin{array}{l}\text { Coded } \\
\text { values }\end{array}$ & Actual value & \\
\cline { 2 - 3 } & $\mathbf{X}_{\mathbf{1}}$ & $\mathbf{X}_{2}$ \\
\cline { 2 - 3 } & Concentration of Kollidon & Concentration of Eudragit \\
& SR per tablet (mg) & RS per tablet $(\mathbf{m g})$ \\
\hline-1 & 30 & 0 \\
0 & 50 & 10 \\
1 & 70 & 20 \\
\hline
\end{tabular}

SR: Sustained release
Nine batches were prepared as per Table 3, wherein the amount of polymers Kollidon SR (X1) and Eudragit RS (X2) were varied to compare the rate of drug release. The blend was prepared by mixing drug and excipients in a laboratory cube blender for $15 \mathrm{~min}$ and finally magnesium stearate and aerosil were blended into. The blends were evaluated for precompression parameters such as bulk density, tapped density, angle of repose, and Carr's compressibility index. The final weight of the tablet was $170 \mathrm{mg}$, compressed using Rimek Mini Press II MT (Karnavati Engineering Private Ltd.) [8,9].

\section{Formulation of bilayered tablet of atorvastatin calcium and metoprolol succinate}

To prepare the bilayered tablet, first the SR blend of metoprolol succinate was added manually into the die cavity of the tablet compression machine (Rimek Mini Press II MT (Karnavati Engineering Private Ltd.) and compressed lightly. Followed by which the IR blend of atorvastatin calcium was added and compressed to obtain the bilayered tablet. All the nine batches of SR metoprolol succinate SR layer were compressed with the optimized batch AT01 of IR and were further evaluated for post-compression characteristics [9].

Evaluation of post-compression parameters of bilayered tablet Physical tests such as hardness, thickness, friability, and uniformity of weight were performed as per USP using Monsanto hardness tester (Pathak Electrical Works), Vernier caliper (Bliss Classic), and Roche Friabilator (Pathak Electricals), respectively [8-10]

\section{Drug excipient compatibility}

Drug-excipient compatibility was determined using Fourier transform infrared and differential scanning calorimetry (DSC) studies.

\section{Drug content}

UV spectrophotometric method for simultaneous estimation of atorvastatin calcium and metoprolol succinate was developed on the guidelines of the method as per Wankhede et al. The tablet was crushed, contents extracted with methanol, and further diluted with phosphate buffer pH 6.8 and drug content analyzed [11].

\section{In vitro disintegration time}

Disintegration time for IR layer of atorvastatin calcium was determined using USP tablet disintegration apparatus with phosphate buffer of pH 6.8 as medium. The volume of medium used was $900 \mathrm{~mL}$ and temperature was $37 \pm 0.5^{\circ} \mathrm{C}$. The time taken for complete disintegration of the IR layer was measured [10].

\section{In vitro drug release}

The in vitro drug release of bilayered tablet was studied using USP type II paddle apparatus using $900 \mathrm{ml}$ phosphate buffer $\mathrm{pH} 6.8$ at $50 \mathrm{rpm}$ at $37 \pm 0.5^{\circ} \mathrm{C}$ (OGD dissolution method). The samples were withdrawn at predetermined time intervals for a period of $24 \mathrm{~h}$ and replaced with the fresh buffer. The samples were filtered through $0.45 \mu \mathrm{m}$ membrane filter, suitably diluted, and analyzed using double beam UV-visible spectrophotometer. The content of drug was calculated using the simultaneous equation method developed and validated for the drug combination. The test was performed in triplicate. Since reproducible

Table 3: Formulation blends of metoprolol succinate layer

\begin{tabular}{|c|c|c|c|c|c|c|c|c|c|}
\hline Ingredients & MS01 & MS02 & MS03 & MS04 & MS05 & MS06 & MS07 & MS08 & MS09 \\
\hline Metoprolol succinate & 47.5 & 47.5 & 47.5 & 47.5 & 47.5 & 47.5 & 47.5 & 47.5 & 47.5 \\
\hline Kollidon SR & 30 & 50 & 70 & 30 & 50 & 70 & 30 & 50 & 70 \\
\hline Eudragit RS 100 & 0 & 0 & 0 & 10 & 10 & 10 & 20 & 20 & 20 \\
\hline MCC pH 102 & 89 & 69 & 49 & 79 & 59 & 39 & 69 & 49 & 29 \\
\hline Magnesium stearate & 1.5 & 1.5 & 1.5 & 1.5 & 1.5 & 1.5 & 1.5 & 1.5 & 1.5 \\
\hline Aerosil & 1 & 1 & 1 & 1 & 1 & 1 & 1 & 1 & 1 \\
\hline Sunset yellow FCF & 1 & 1 & 1 & 1 & 1 & 1 & 1 & 1 & 1 \\
\hline
\end{tabular}

SR: Sustained release 
data were obtained (standard deviation $\pm 4 \%$ ), hence average values were considered.

\section{Statistical analysis}

The statistical analysis was done using Design Expert ${ }^{\circledR} 10$ software. The responses analyzed were the drug release Q2 (at $2 \mathrm{~h}$ ), Q8 (at $8 \mathrm{~h}$ ), and Q20 (20 h). Contribution of each factor was evaluated as responses, and graphical representation was seen through the contour plots and 3D surface plots. Contribution of each factor on the responses was evaluated by two-way analysis of variance (ANOVA). The significance level was considered as $\mathrm{p}<0.05$ [10].

\section{Kinetic modeling for drug release}

Mechanism of drug release was studied by analyzing the dissolution data through zero order, first order, and Higuchi's and KorsmeyerPeppas equations [12].

\section{Accelerated stability study}

The optimized batch of bilayered tablet was subjected to stability study in accordance with ICH guidelines. The bilayered tablets wrapped in aluminum foil were kept at $40^{\circ} \mathrm{C}, 75 \% \mathrm{RH}$ in a stability chamber (Patel Scientific Instruments) for 3 months. Subsequently, the tablets were analyzed for drug content, in vitro release, and other physicochemical characteristics.

\section{RESULTS AND DISCUSSION}

Pre-compression characteristics such as bulk density, tapped density, angle of repose, and Carr's compressibility index were evaluated for both the blends and are tabulated in Tables 4 and 5 . The angle of repose and Carr's compressibility values indicated good flow properties and compressibility of both the blends. The angle of repose ranges from $22.04 \pm 0.55$ to $23.67 \pm 0.98$ and $12.64 \pm 0.55$ to $21.57 \pm 0.62$ for IR and SR blends, respectively. The SR blends exhibit better flow properties as the amount of Kollidon SR polymer increases from 30 to $70 \mathrm{mg}$ per tablet which makes Kollidon SR a good directly compressible excipient.

\section{Post-compression characteristics of bilayered tablet}

The results of post-compression characteristics - hardness, thickness, weight variation, friability, disintegration time (for IR layer), and drug content are as tabulated in Table 6. A linear relationship was observed between the concentration of Kollidon SR and the hardness of the tablet. The IR component of the bilayer tablet disintegrates within $90-110 \mathrm{~s}$ as required for the formulation.

\section{Drug excipient compatibility}

DSC studies

From the DSC study, the thermograph shows the melting point of pure drug metoprolol succinate was found at $138^{\circ} \mathrm{C}$; atorvastatin calcium was at $159.95^{\circ} \mathrm{C}$ which is similar as reported in the literature. The results of DSC study are as depicted in Fig. 1. The thermograph of pure drugs and mixture of drugs does not show a significant change in their respective melting points. The DSC study of formulation mixtures also shows no significant change to that of the melting point of pure drug, which rules out drug excipient incompatibilities.

\section{In vitro drug release}

The cumulative percent drug released for AT01, AT02, AT03, and AT04 formulations was found to be $100.87 \%, 71.11 \%, 85.97 \%$, and $46.42 \%$, respectively, at $45 \mathrm{~min}$. The results as depicted in Fig. 2 show that the maximum amount of drug was released from the formulation AT01

Table 4: Pre-compression characteristics of atorvastatin calcium blends

\begin{tabular}{llll}
\hline Formulation code & Angle of repose ${ }^{\mathbf{a}}$ & ${\text { Bulk density }(\mathrm{g} / \mathrm{ml})^{\mathbf{a}}}$ & Tapped density $^{\mathrm{a}}(\mathrm{g} / \mathbf{m l})$ \\
\hline AT01 & $22.04 \pm 0.55$ & $0.43 \pm 0.05$ & $0.54 \pm 0.02$ \\
AT02 & $21.54 \pm 0.41$ & $0.47 \pm 0.04$ & $0.55 \pm 0.08$ \\
AT03 & $23.67 \pm 0.98$ & $0.42 \pm 0.08$ & $0.54 \pm 0.06$ \\
AT04 & $22.87 \pm 0.71$ & $0.41 \pm 0.04$ & $0.52 \pm 0.04$ \\
\hline
\end{tabular}

aMean \pm SD, $n=3$. SD: Standard deviation

Table 5: Pre-compression characteristics of metoprolol succinate blends

\begin{tabular}{llll}
\hline Formulation code & Angle of repose $^{\mathbf{a}}$ & Bulk density $^{\mathrm{a}} \mathbf{( g / m l )}$ & Tapped density $^{\mathrm{a}}$ (g/ml) \\
\hline MS01 & $21.57 \pm 0.62$ & $0.41 \pm 0.08$ & $0.46 \pm 0.04$ \\
MS02 & $20.14 \pm 0.22$ & $0.42 \pm 0.05$ & $0.48 \pm 0.11$ \\
MS03 & $18.54 \pm 0.87$ & $0.43 \pm 0.07$ & $0.49 \pm 0.09$ \\
MS04 & $19.31 \pm 1.0$ & $0.38 \pm 0.1$ & $0.42 \pm 0.08$ \\
MS05 & $18.54 \pm 0.32$ & $0.36 \pm 0.08$ & $0.41 \pm 0.06$ \\
MS06 & $16.66 \pm 0.54$ & $0.35 \pm 0.04$ & $0.42 \pm 0.05$ \\
MS07 & $15.41 \pm 0.87$ & $0.36 \pm 0.09$ & $0.40 \pm 0.08$ \\
MS08 & $12.64 \pm 0.55$ & $0.34 \pm 0.08$ & $0.39 \pm 0.09$ \\
MS09 & $14.65 \pm 0.21$ & $0.33 \pm 0.04$ & $0.38 \pm 0.24$ \\
\hline
\end{tabular}

${ }^{a}$ Mean \pm SD, n=3. SD: Standard deviation

Table 6: Post compression characteristics of bilayered tablet

\begin{tabular}{|c|c|c|c|c|c|c|c|}
\hline $\begin{array}{l}\text { Formulation } \\
\text { code }\end{array}$ & $\begin{array}{l}\text { Hardness } \\
\left(\mathrm{kg} / \mathrm{cm}^{2}\right)^{\mathrm{a}}\end{array}$ & $\begin{array}{l}\text { Thickness } \\
\text { (mm) }\end{array}$ & $\begin{array}{l}\text { Weight } \\
\text { variation }^{\mathrm{a}}(\mathrm{mg})\end{array}$ & Friability $^{\mathrm{a}}(\%)$ & $\begin{array}{l}\text { DT for IR } \\
\text { layer (s) }\end{array}$ & $\begin{array}{l}\text { Drug content } \\
\text { (SR layer) }(\%)\end{array}$ & $\begin{array}{l}\text { Drug content } \\
\text { (IR layer) (\%) }\end{array}$ \\
\hline MS01 & $8.5 \pm 0.23$ & 4 & $280 \pm 0.52$ & $0.29 \pm 0.0021$ & 90 & $98.12 \pm 0.87$ & $99.21 \pm 0.57$ \\
\hline MS02 & $10.3 \pm 0.35$ & 4 & $280 \pm 0.37$ & $0.41 \pm 0.0074$ & 98 & $99.87 \pm 1.21$ & $99.57 \pm 0.64$ \\
\hline MS03 & $11.2 \pm 0.87$ & 4 & $280 \pm 0.97$ & $0.51 \pm 0.0041$ & 95 & $99.35 \pm 0.54$ & $98.64 \pm 1.28$ \\
\hline MS04 & $10.5 \pm 0.47$ & 4 & $280 \pm 0.65$ & $0.38 \pm 0.005$ & 97 & $99.84 \pm 0.98$ & $99.24 \pm 0.55$ \\
\hline MS05 & $11.0 \pm 0.17$ & 4 & $280 \pm 0.86$ & $0.63 \pm 0.0087$ & 100 & $98.67 \pm 1.32$ & $98.54 \pm 0.97$ \\
\hline MS06 & $10.1 \pm 0.61$ & 4 & $280 \pm 0.46$ & $0.49 \pm 0.0097$ & 93 & $98.12 \pm 1.5$ & $99.69 \pm 1.64$ \\
\hline MS08 & $11.0 \pm 0.45$ & 4 & $280 \pm 0.87$ & $0.17 \pm 0.0047$ & 110 & $99.54 \pm 0.68$ & $99.16 \pm 0.57$ \\
\hline MS09 & $11.4 \pm 0.36$ & 4 & $280 \pm 0.14$ & $0.26 \pm 0.0046$ & 98 & $99.34 \pm 0.41$ & $98.54 \pm 1.22$ \\
\hline
\end{tabular}

aMean \pm SD, n=3. SD: Standard deviation 


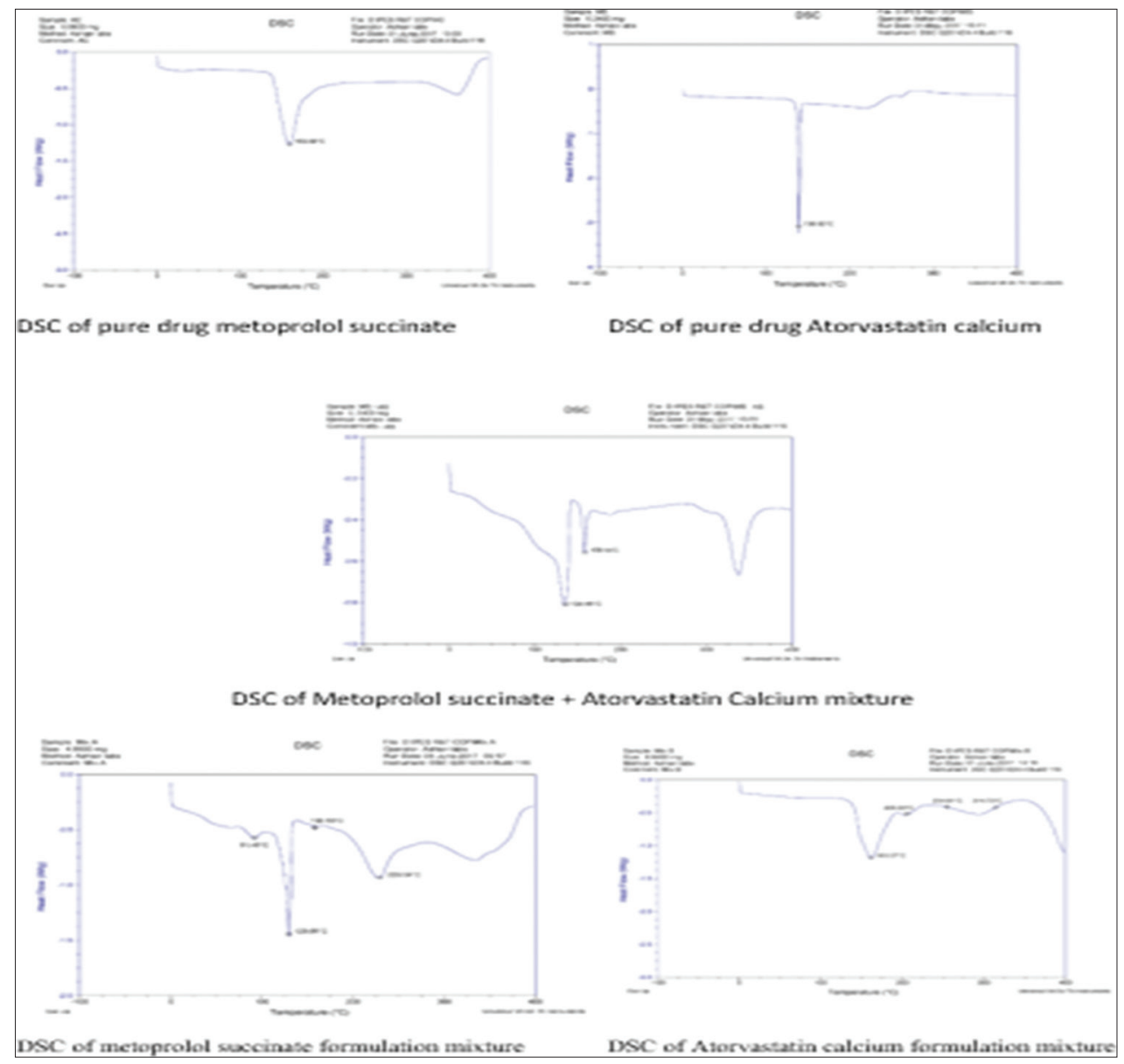

Fig. 1: Compatibility studies of drugs and excipients using differential scanning calorimetry

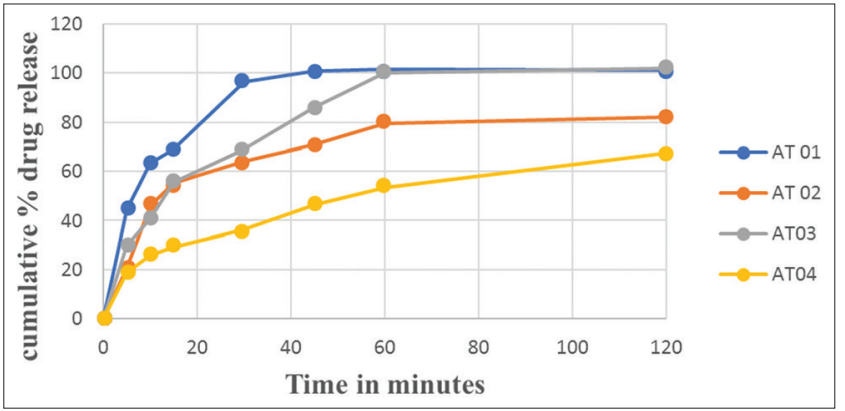

Fig. 2: Cumulative drug release profiles of atorvastatin calcium immediate release component

when compared to other formulations. This is due to the optimum concentration level of superdisintegrant crospovidone and surfactant sodium lauryl sulfate in the formulation. Hence, formulation AT01 was confirmed as an optimized IR layer, which was further selected to be compressed against the nine batches of SR layer of metoprolol succinate as designed using Design Expert Software.

The release profile of the SR metoprolol succinate component from the nine batches of bilayer tablets is as given in Fig. 3. All the factorial batches showed drug release up to 12-24 h depending on the concentration of Kollidon SR polymer. Formulation MS01, MS04, and MS07 showed a rapid dissolution profile from 12 to $18 \mathrm{~h}$ which was faster than the required release for a once a day formulation. These three batches contain $18 \%$ of Kollidon SR which is insufficient to control the release up to $24 \mathrm{~h}$. The rest of the batches controlled the drug release up to 24 h, with Kollidon SR concentration varying between $30 \%$ and $40 \%$
(50-70 mg per tablet). Kollidon SR showed excellent controlled drug release in this range. Formulation MS06 showed optimum drug release of $94.31 \%$ at $24 \mathrm{~h}$ with $\mathrm{f} 2$ value of 74 when compared to marketed formulation (Metpure XL) and complying with USP requirements for release as given in Table 7. Eudragit RS plays a significant role as to control the burst release that occurs in the initial hour. It was observed that formulations MS01, MS02, and MS03 with Kollidon SR polymer and devoid of Eudragit RS, showed a significant burst release effect in the initial 1-2 $\mathrm{h}$ of release as compared to the rest of the formulations. The release for formulations MS01, MS02 and MS03 at end of 1 hour was $31.23 \%, 25.22 \%$ and $22.02 \%$ respectively which is not in the desired limit of not more than $25 \%$ as per USP requirements (Table 7). Kollidon SR, is a polymer containing $80 \%$ insoluble PVA and $20 \%$ soluble PVP. When in contact of the dissolution media the water soluble PVP dissolves forming pores for release of the dug. The sudden burst effect has been attributed due to this phenomenon. Inclusion of Eudragit RS into the formulation controls the burst release and aids kollidon SR in controlling the drug release over a 24 hour period. For formulations MS05, MS06, MS08 and MS09 containing 10-20mg of Eudragit RS per tablet the release at the end of 1 hour was $22.44 \%, 16.82 \%, 21.45 \%$ and $10.55 \%$ respectively. This clearly envisages the role of Eudragit RS in controlling the burst release which was observed with Kollidon SR alone. The release profile of the optimum batch MS06 of bilayer tablet is depicted in Fig. 4. The Immediate release atorvastatin component releases $100.87 \%$ the drug in $45 \mathrm{~min}$ whereas the release of metoprolol succinate component is sustained upto $24 \mathrm{~h} 0 \mathrm{urr}$.

The in vitro release data were fitted into various kinetic equations. The correlation coefficients are indicated in Table 8. It can be postulated that in vitro release profile of all the metoprolol succinate matrix formulations could be best expressed by the Higuchi model. The plot showed high linearity in comparison to other release kinetic equations. 


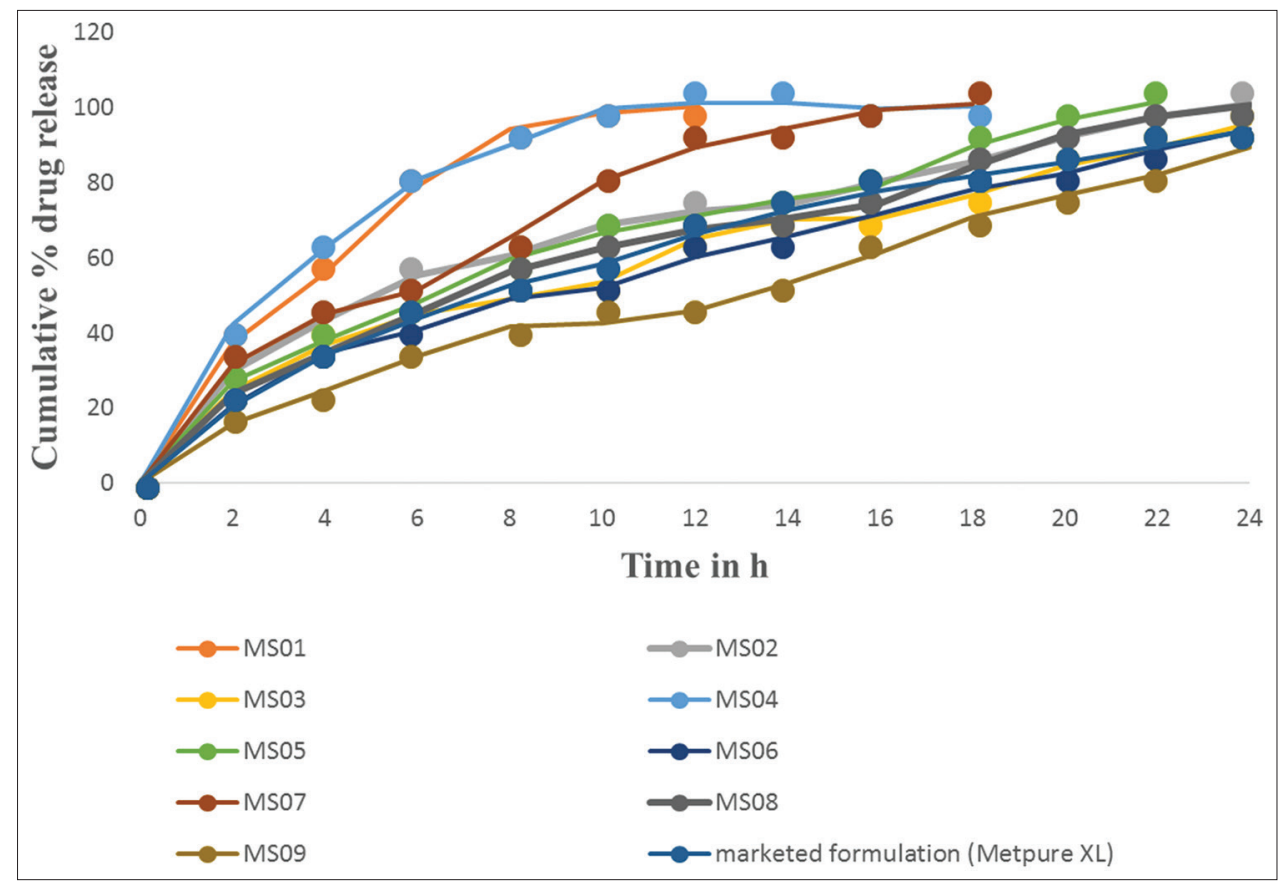

Fig 3: Cumulative drug release profiles of metoprolol succinate sustained release component

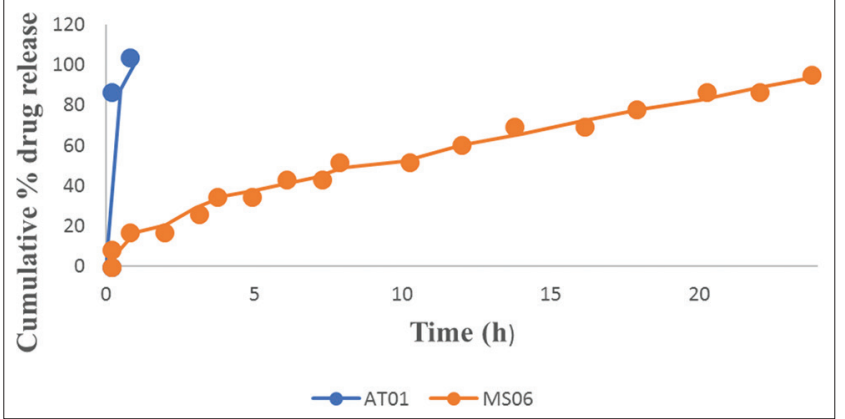

Fig. 4. Dissolution profile of optimized batch of bilayer tablet

Table 7: USP requirements for release of metoprolol succinate extended release

\begin{tabular}{ll}
\hline Time (h) & Amount dissolved \\
\hline 1 & NMT 25\% \\
4 & $20-40 \%$ \\
8 & $40-60 \%$ \\
20 & NLT $80 \%$ \\
\hline
\end{tabular}

Release of drug from the matrix tablet generally follows diffusion for water soluble drug. To confirm diffusion mechanism, the data were fitted into Korsmeyer et al's equation. For matrix tablet, n value 0.5 indicates diffusion controlled value to near 1.00 indicates erosion. Intermediate value suggests simultaneous diffusion and erosion contributed to overall release mechanism.

\section{Statistical optimization of the bilayer tablet}

To describe the entire dissolution profile, three time points were considered in the design expert software. Percentages of drug release at 2, 8, and $20 \mathrm{~h}(\mathrm{Q} 2, \mathrm{Q} 8$, and Q20) were considered as responses as tabulated in Table 9. As observed formulations MS02, MS03, MS05, MS06, and MS08 control the drug release up to a $24 \mathrm{~h}$ period. This is mainly attributed the excellent control release property of Kollidon SR polymer. Further, Eudragit RS helps control the burst release significantly as observed in formulation MS06.

\section{ANOVA}

ANOVA of the responses indicated that response surface models developed for Q2, Q8, and Q20 was significant and adequate. Influence of variables on the responses is indicated in Table 10. From the ANOVA analysis, it can be observed that Kollidon SR polymer has effect on all responses Q2, Q8, and Q20 (since $\mathrm{p}<0.5$ ). This enforces the fact that it is the main release-retarding polymer that controls the drug release up to $24 \mathrm{~h}$. It is also observed from the ANOVA result that Eudragit RS has a significant effect at Q2. This reinforces the significant role of the polymer to control the burst release of the drug in the initial $2 \mathrm{~h}$. Eudragit RS has a less significant effect on drug release at response Q8 and Q20.

\section{Model summary statistics}

Model summary statistics for the selected significant models are shown in Table $11 . \mathrm{R}^{2}$ values indicate a high level of correlation between experimental and predicted responses. The closeness of the adjusted and predicted $\mathrm{R}^{2}$ values explains the reliability of the model.

\section{Mathematical equations}

Mathematical relationships generated from design expert for the studied response variables are expressed as equations I, II, and III. The equation in terms of actual factors can be used to make predictions about the response for given levels of each factor.

$$
\begin{aligned}
& \text { Q2 }=+52.51639-0.41925 * X 1-0.34583 * X 2 \ldots \ldots . . I \\
& Q 8=+115.46194-0.91958 * X 1-0.66917 * X 2 \ldots \ldots . . . I I \\
& \text { Q20 }=+116.51556-0.47283^{*} X 1-0.12283^{*} \text { X2 .....III }
\end{aligned}
$$

\section{Response surface analysis}

Figs. 6-11 represent the contour plot and three dimensional analysis for the studied response properties of release at $2 \mathrm{~h}, 8 \mathrm{~h}$ and $20 \mathrm{~h}$. From the contour plot it can be concluded that the release in $2 \mathrm{~h}$ decreases with augmentation of both the variables, concentration of Kollidon SR and Concentration of Eudragit RS. Eudragit RS is observed to control the burst release in the initial 1-2 $\mathrm{h}$. This effect is significantly observed in the Q2 response after which it can be observed that Kollidon SR is primarily involved in controlling the release. From the contour plot it was evident that the declining trend was obtained with ascending 


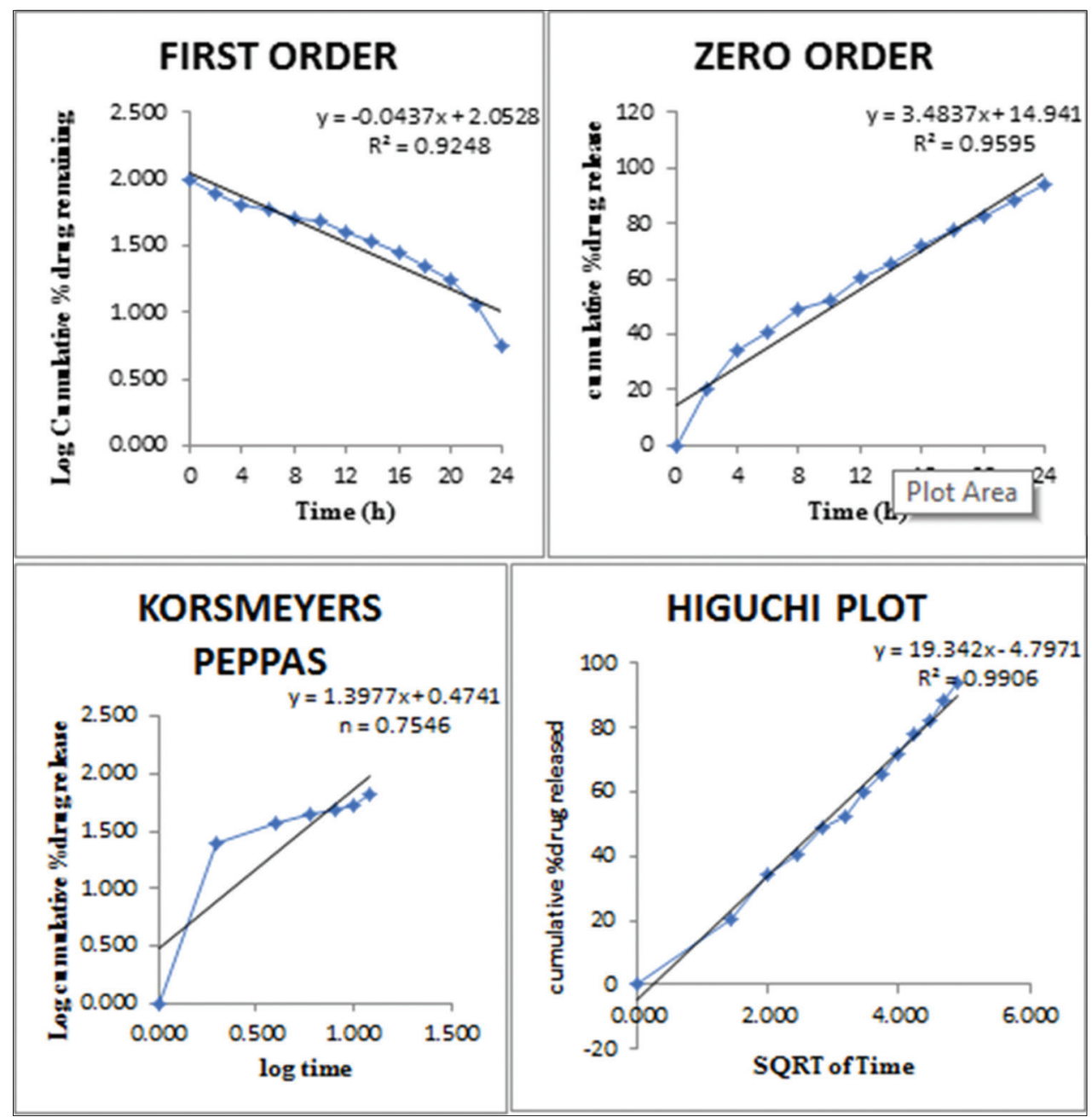

Fig. 5: Release kinetics of optimized batch MS06

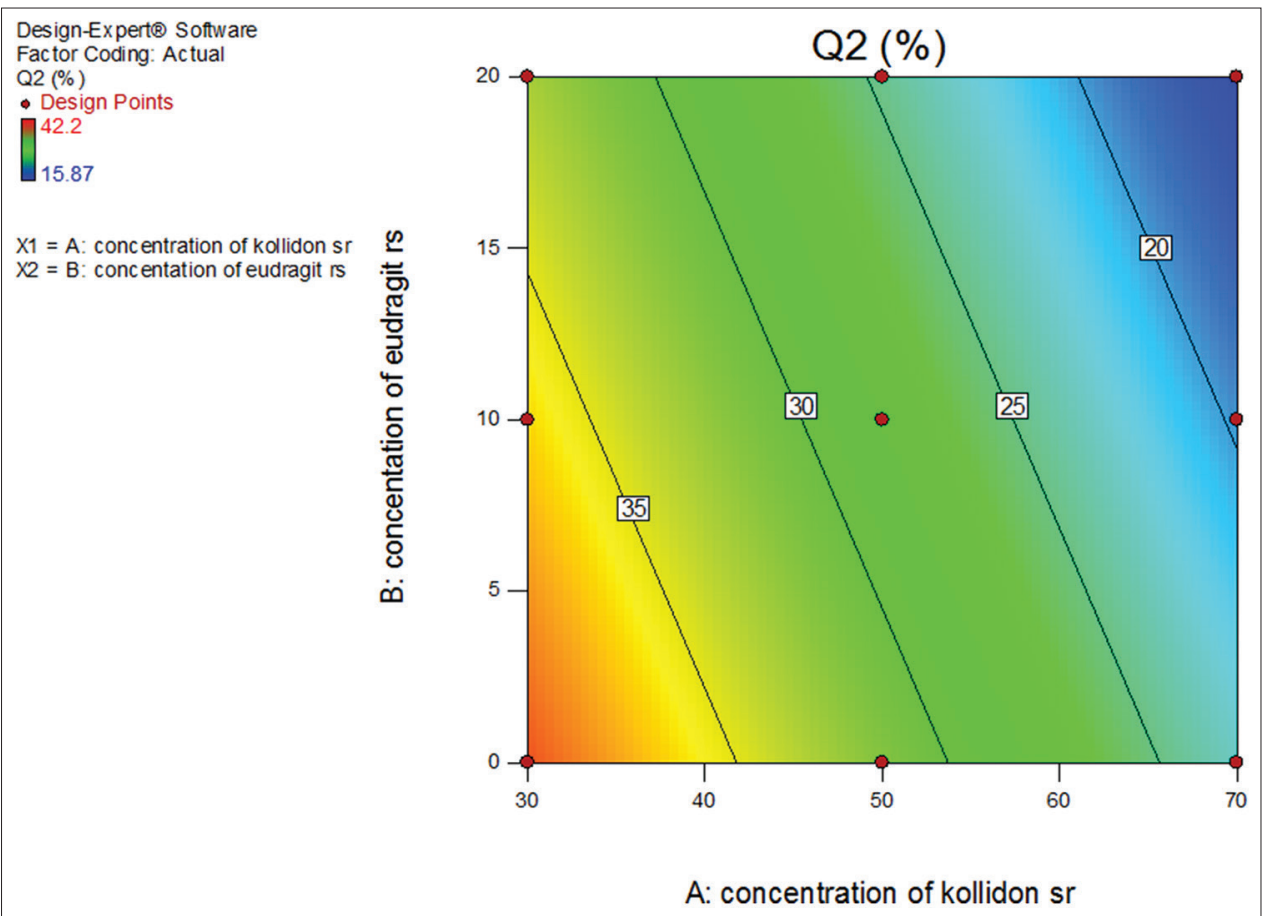

Fig. 6: Contour plot for response Q2 


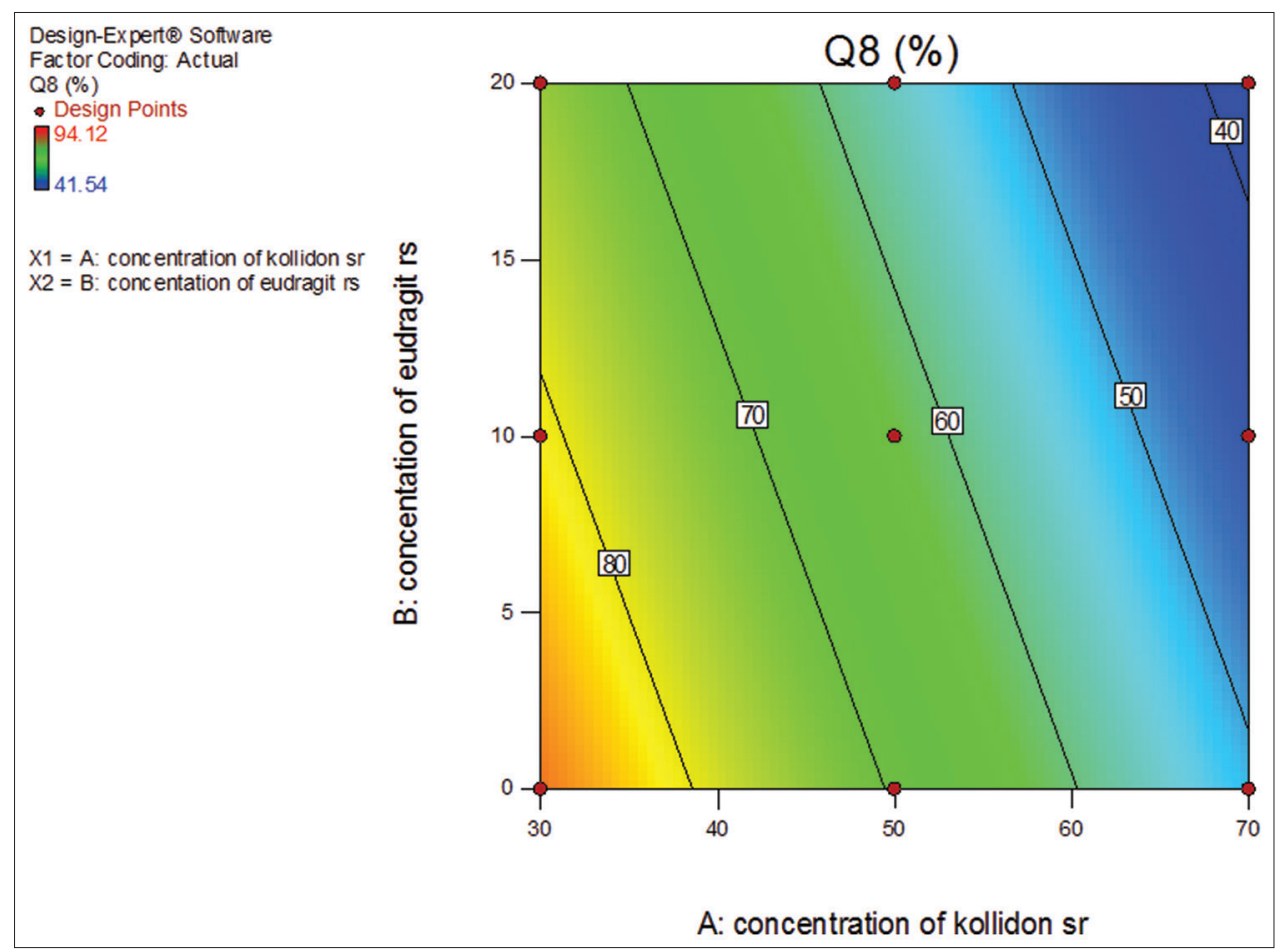

Fig. 7: Contour plot for response $Q 8$

Table 8: Correlation coefficients of different pharmacokinetic models for release

\begin{tabular}{llllll}
\hline Formulation & Zero order $\left(\mathbf{r}^{2}\right)$ & First order $\left(\mathbf{r}^{2}\right)$ & Higuchi $\left(\mathbf{r}^{2}\right)$ & Peppas $(\mathbf{n})$ & Hixon Crowel $\left(\mathbf{r}^{2}\right)$ \\
\hline MS01 & 0.6401 & 0.786 & 0.8594 & 0.7569 & 0.8973 \\
MS02 & 0.8975 & 0.8524 & 0.9942 & 0.7436 & 0.8891 \\
MS03 & 0.9439 & 0.8947 & 0.9908 & 0.7546 & 0.9621 \\
MS04 & 0.5828 & 0.6618 & 0.8228 & 0.7331 & 0.7757 \\
MS05 & 0.9365 & 0.8639 & 0.9943 & 0.7656 & 0.8113 \\
MS06 & 0.9595 & 0.9248 & 0.9906 & 0.7546 & 0.9621 \\
MS07 & 0.8421 & 0.9051 & 0.9625 & 0.766 & 0.9379 \\
MS08 & 0.9483 & 0.8371 & 0.9906 & 0.7848 & 0.8128 \\
MS09 & 0.9814 & 0.9177 & 0.9559 & 0.8069 & 0.9617 \\
\hline
\end{tabular}

Table 9: Percentage drug responses at $2 \mathrm{~h}, 8 \mathrm{~h}$, and $20 \mathrm{~h}$

\begin{tabular}{llll}
\hline Formulation code & Q2 (\%) & Q8 (\%) & Q20 (\%) \\
\hline MS01 & 37.46 & 94.12 & 100 \\
MS02 & 29.87 & 60.47 & 92.17 \\
MS03 & 24.5 & 48.8 & 84.38 \\
MS04 & 42.2 & 90.05 & 100 \\
MS05 & 27.21 & 59.47 & 96.74 \\
MS06 & 20.54 & 48.97 & 82.34 \\
MS07 & 31.56 & 65.49 & 100 \\
MS08 & 23.65 & 56.21 & 92.64 \\
MS09 & 15.87 & 41.54 & 76.54 \\
\hline
\end{tabular}

order of Kollidon SR. The plots for Q8 and Q20 demonstrate that the concentration of kollidon SR significantly controls the release of metoprolol succinate from the matrix formulation after 2 hours. As observed from the surface response plots, as the concentration of Kollidon SR increases from $30 \mathrm{mg} /$ tablet to $70 \mathrm{mg} /$ tablet, the release at the response points is retarded. The contour plot of Q8 and Q20 as well as the surface response plot shows major role of Kollidon SR controlling the drug release. This is mainly attributed to the plastic behaviour of the hydrophobic polymer PVA in Kollidon SR which shows effect is controlling drug release of a water soluble drug metoprolol succinate from the matrix formulation.
Table 10: ANOVA influence of formulation variables on response factors

\begin{tabular}{lll}
\hline Response factor & F value & P>F \\
\hline Q2 & 30.73 & 0.0007 \\
X1 (Kollidon SR concentration) & 52.52 & 0.0004 \\
X2 (Eudragit RS concentration) & 8.93 & 0.0244 \\
Q8 & 20.78 & 0.0020 \\
X1 (Kollidon SR concentration) & 36.71 & 0.0009 \\
X2 (Eudragit RS concentration) & 4.86 & 0.0697 \\
Q20 & 27.96 & 0.0009 \\
X1 (Kollidon SR concentration) & 54.99 & 0.0003 \\
X2 (Eudragit RS concentration) & 0.93 & 0.3726 \\
\hline
\end{tabular}

SR: Sustained release, ANOVA: Analysis of variance

Table 11: Model summary - influence of formulation variables on response factors

\begin{tabular}{llll}
\hline Response & SD & Adjusted $\mathbf{R}^{2}$ & Predicted $\mathbf{R}^{2}$ \\
\hline Q2 & 8.229 & 0.8814 & 0.8055 \\
Q8 & 18.131 & 0.8318 & 0.6905 \\
Q20 & 8.690 & 0.8708 & 0.7855 \\
\hline
\end{tabular}

SD: Standard deviation 


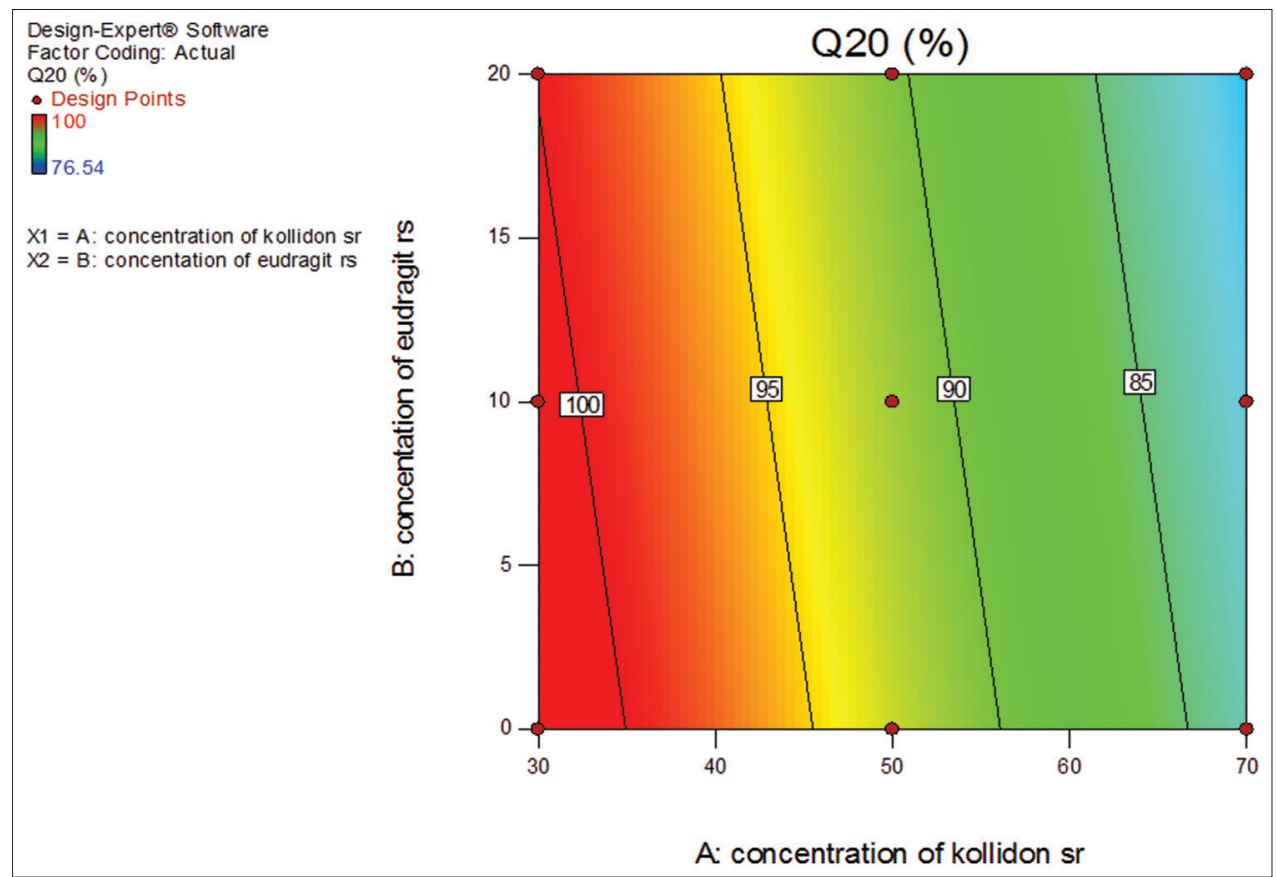

Fig. 8: Contour plot for response Q20

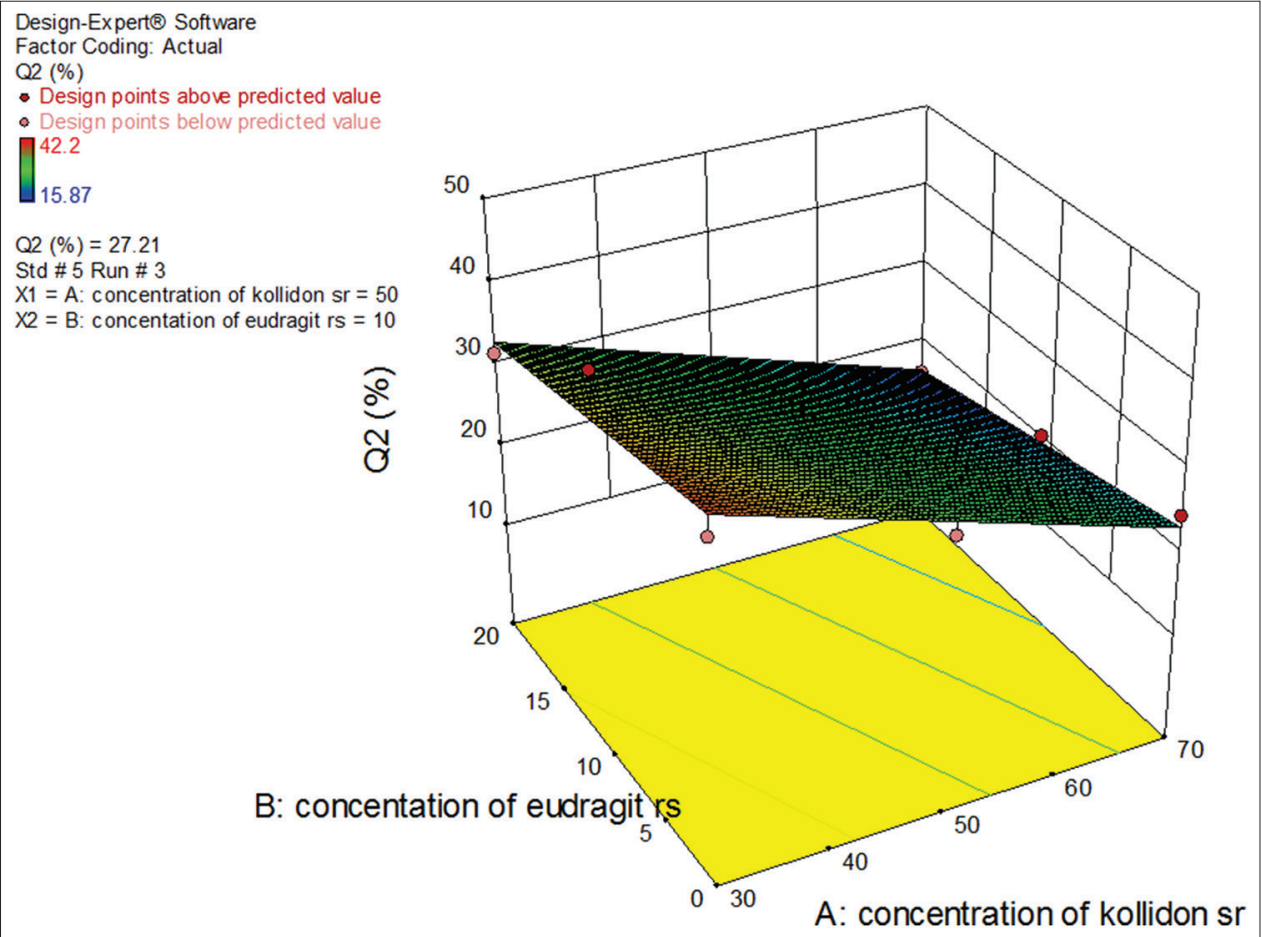

Fig. 9: Surface response plot for response Q2

\section{CONCLUSION}

The contour plots and response surface methodology using Design-Expert Software were used to optimize the bilayer tablet of metoprolol succinate SR and atorvastatin calcium IR wherein the work envisages the use of the Kollidon SR polymer as a significant polymer for direct compression of the bilayer tablet. It controls the release of water-soluble metoprolol succinate drug for the desired period of time. With the advantage of $\mathrm{pH}$-independent release, it can control the drug release up to $24 \mathrm{~h}$. Further, Eudragit
RS reinforces the effect in addition to controlling the burst effect in the formulations with Kollidon alone. Formulation MS06 with $70 \mathrm{mg}$ Kollidon SR and $10 \mathrm{mg}$ Eudragit RS is the best optimized formulation. The influence of the factors can be closely studied on the responses, i.e., drug release at various time points. The direct compression technique for manufacture of this bilayer tablet is a safe and effective tool for patients taking the drugs as monotherapy as well as for drugs which can be given as fixed-dose combinations for lifestyle diseases. 


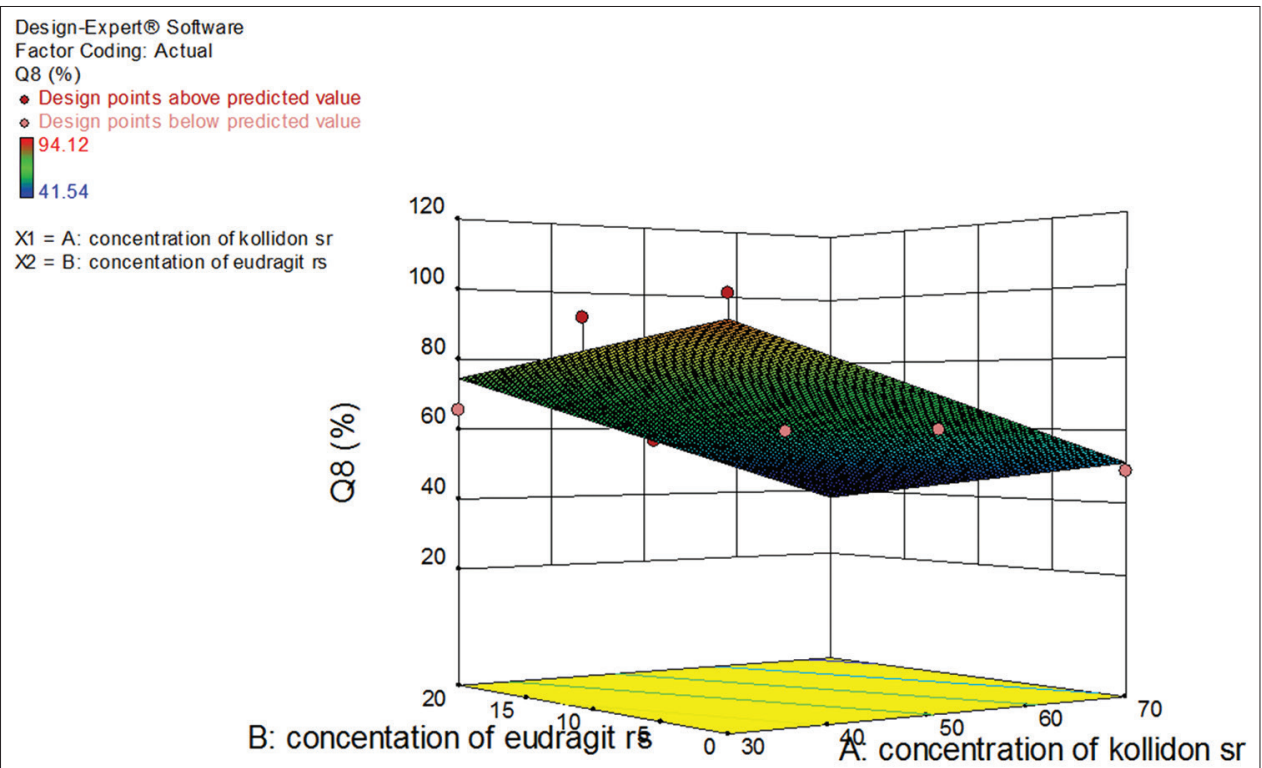

Fig. 10: Surface response plot for response Q8

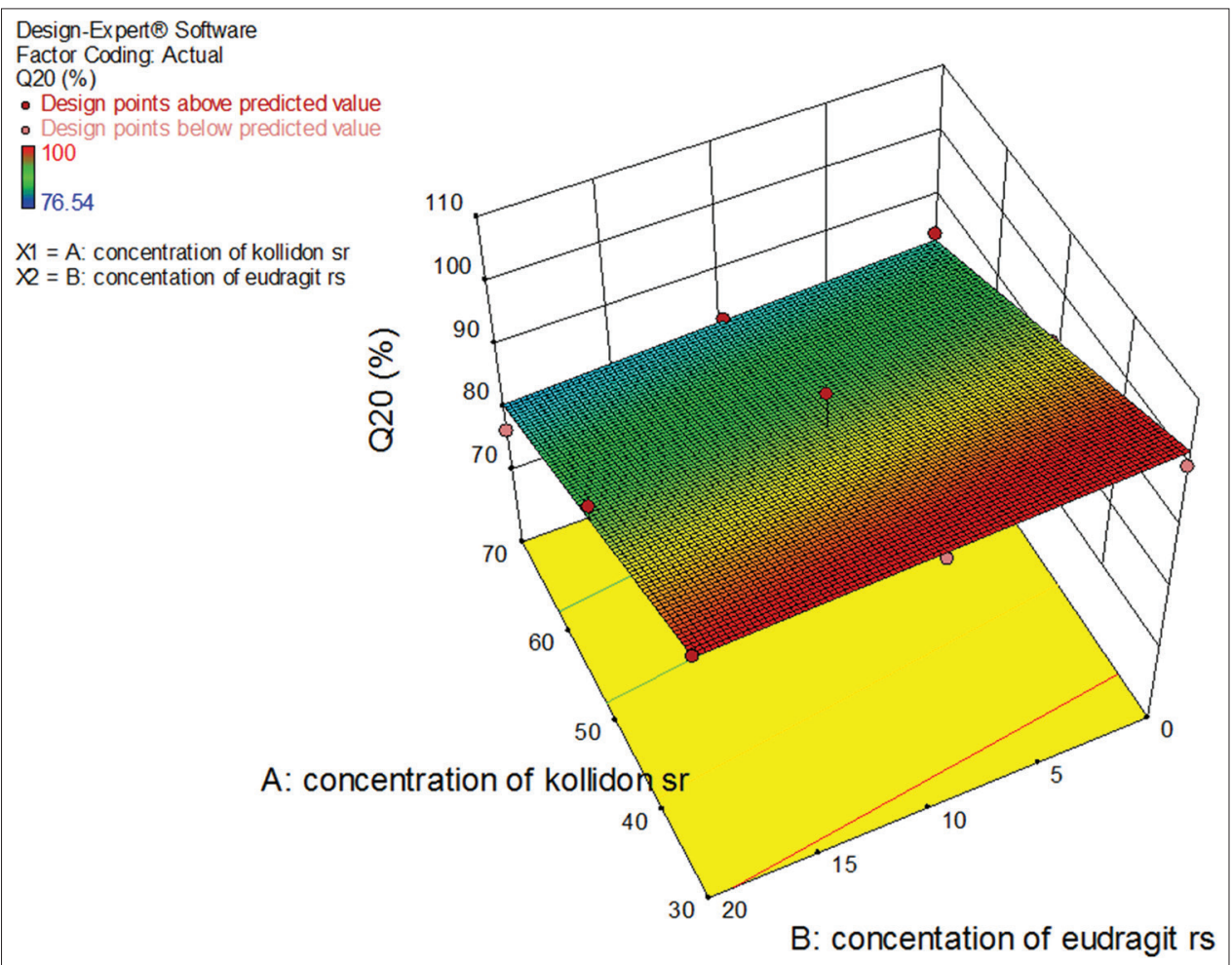

Fig. 11: Surface response plot for response Q20

\section{ACKNOWLEDGMENT}

I would like to thank my Principal Dr. S. N. Mamle Dessai for granting permission to use the institute facilities to carry out my research work. My sincere gratitude to my guide Dr. H. M. Tank, for his guidance and support throughout the work.

\section{CONFLICT OF INTEREST}

All authors have none to declare.

\section{AUTHORS CONTRIBUTION}

Pearl Pires Dighe, corresponding author for this publication, working as Assistant Professor has carried out all the above research work in the premises of PES's Rajaram and tarabai Bandekar College of Pharmacy under the guidance of her Ph.D guide Dr. H.M.Tank, Principal, Matushree V. B. Manvar College of Pharmacy, Dumiyani, Upleta, Dist. Rajkot

\section{REFERENCES}

1. Vishwakarma AG, Mogal RT, Pawar AY. Bi-Layer tablet - A new ways in oral drug delivery system. Int J Pharm Tech Res 2014;6:1416-28.

2. Chobanian AV, Bakris GL, Black HR, Cushman WC, Green LA, Izzo JL, et al. Seventh report of the joint national committee on prevention, detection, evaluation, and treatment of high blood pressure. Hypertension 2003;42:1206-52.

3. Deshmukh VN, Singh SP, Sakarkar DM. Formulation and evaluation of sustained release metoprolol succinate tablet using hydrophilic gums as release modifiers. Int J Pharm Tech Res 2009;1:159-63. 
4. Nirmal J, Saisivam S, Peddanna C, Muralidharan S, Godwinkumar S, Nagarajan $\mathrm{M}$, et al. Bilayer tablets of atorvastatin calcium and nicotinic acid: Formulation and evaluation. Chem Pharm Bull (Tokyo) 2008;56:1455-8.

5. Chandragiri AK, Kaluvala $\mathrm{T}$, Nagabandi V, et al. Formulation development of fixed dose combination of Metoprolol succinate extended release pellets and atorvastatin calcium immediate release drugs. Am J Pharm Tech Res 2014;4:576-87.

6. Jain SK, Kadam VJ, Hirelekar RS. Study of effects of post-compression curing on Kollidon SR based floating tablets. Int J Pharm Pharm Sci 2011;3:90-3.

7. Arunprashad B, Teja GK. Design and evaluation of bilayer tablets to treat respiratory tract infection. Int J Pharm Pharm Sci 2013;5:250-5.

8. Brito SR, Sravani G, Bhanupriya N, Veerupakshi M, Anil KB, Wasim RS. Design and evaluation of sustained release bilayer tablet of Metformin hydrochloride with Metoprolol tartrate. Intl J Novel Tr Pharm Sci 2011; 1: 10-6.

9. Sanjit KR, Naskar S, Kundu S, Kpoutsu K. Formulation and evaluation of sustained release bilayer tablets of propranolol hydrochloride. Int J Pharm Pharm Sci 2015; 7:264-9.

10. Jivani RR, Patel CN, Jivani NP. Statistical design of experiments on fabrication of bilayer tablet of narrow absorption window drug: Development and in vitro characterisation. Indian J Pharm Sci 2012;74:302-11.

11. Wankhede SB, Dixit NR, Chitlange SS. Validated spectrophotometric methods for quantitative determination of atorvastatin calcium and metoprolol succinate in capsules. Pharm Chem 2010;2:134-40.

12. Chime SA, Onunkwo GC, Onyishi II. Kinetics and mechanisms of drug release from swellable and non swellable matrices: A review. Res J Pharm Biol Chem Sci 2013;2:97-103. 